\title{
No error-free society
}

NoTHING ventured, nothing gained-the calculus of risk and the trade-off between benefit and damage is much in the news at present. This is partly due to the growing public interest in decision-making in the nuclear industry, but some of the credit in Britain must go to the Council for Science and Society (CSS) which has had a study group looking at the question of acceptable risk and which this week convened a public meeting on the subject.

There is something almost irrational in our variable attitudes to risk-taking. The hazards of cigarette smoking are well enough known, are not by any means negligible, often involve others quite involuntarily in a long period of distress and yet are clearly deemed acceptable by a large section of the public. The same might be said of combining drinking with driving. And yet at the other end of the scale those same inveterate risk-takers may show profound shock on hearing of ten people being killed in a coach crash or may express the strongest opposition to the building of a nuclear power station with a claimed minute chance of having a serious accident. We may live in fear of a major accident in which a thousand might die even though, as Reg Farmer pointed out last week (page 93), such an event would barely affect the accidental death rate. It somehow seems that the idea of one or two people being responsible for many deaths strikes a very profound note in the public conscience. Desirable as this is, it inevitably dampens down public concern for how to cut down on the smaller scale accidents.

A frequent rallying cry amongst those concerned with hazards is that as technology grows so does the risk. Even the CSS will say in its working party's report 'popular concern about risks has increased recently, as man-made disasters carry the threat of even worse to come from new or projected technologies'. A more technological world may indeed open up the possibility of human error causing more deaths; the six hundred deaths on Tenerife would have been only one hundred from a similar accident twenty-five years ago. But all in all the fatality rate for air travel has been steadily declining during this same period that the potential for bigger tragedies has been growing, so maybe the intro- duction of new technology, some of which is safetyoriented, has had a beneficial effect.

Because things have improved in one well-studied industry doesn't, of course, mean the same will happen everywhere, and it is obviously right that we should go on asking more and more searching questions about safety. But modern scientific analysis coupled with intensive computer simulation of hazards can easily give the public a false impression that by better and deeper study the present-day technologist can give more and more assured guarantees that anything newly introduced will be 'safe'. As accidents from the trivial to the severe show, however, human actions, logical in themselves but illogical in a broader context, are at the heart of many disasters. These actions can never be properly simulated-who would have put a candle into the computer program for safety at Browns Ferry?

What we have to do if we really want the benefits of new technology is to be prepared for some mistakes to find their own way out-a principle, incidentally, followed throughout the whole process of scientific advance.

Obviously we don't allow a few stored nuclear weapons to go off by accident in order to learn how they can be safely stored, but in many environments, such as factories, air traffic, coal mining, novel engineering structures and so on, it is only with the help of an occasional accident, however distressing, that some very important and valuable pieces of information ever emerge. In an age in which the public expects scientists and technologists to think of everything ahead of time, this idea of learning from mistakes is often forgotten. But to learn effectively, the after-the-fact enquiry must be very wide ranging, because accidents, even road accidents, frequently result from a string of errors, sometimes apparently of little relevance. Thus one requirement, insufficiently widely discussed, in risk reduction is that the scope of enquiries should not be too severely circumscribed. This is a political matter and decisions are often taken against a background of fears of a 'fishing expedition'; maybe there is some good research to be done on how wide committees of enquiry should spread their nets. 